\title{
TÉCNICAS DE RECICLAGEM E MARMORIZAÇÃO DE PAPEL
}

\author{
Techniques of Recycling and Marbling of paper \\ Sérgio Thode Filho', Ana Paula da Silva da Costa², Israel Rodrigues ${ }^{3}$, \\ Azarias Machado de Andrade ${ }^{4}$, Marcelo Fonseca Monteiro de Sena ${ }^{5}$ \\ 'Doutorando em Meio Ambiente pelo PPG-MA da Universidade do Estado do Rio de Janeiro - UERJ, Professor do Instituto Federal de Educação, \\ Ciência e Tecnologia do Rio de Janeiro - IFRJ, Campus Duque de Caxias, RJ, Laboratório Multidisciplinar de Gerenciamento de Resíduos - LMGR \\ ${ }^{2}$ Aluna do Curso Tecnólogo em Gestão Ambiental (CEFET-RJ), bolsista pesquisadora do LMGR \\ ${ }^{3}$ Aluno do Curso Técnico em Química - IFRJ, colaborador do LMGR \\ ${ }^{4}$ Professor do Curso de Engenharia Florestal da Universidade Federal Rural do Rio de Janeiro (UFRRJ) \\ ${ }^{5}$ Professor do Instituto Federal do Rio de Janeiro - IFRJ, Campus Duque de Caxias, RJ - LMGR
}

\begin{abstract}
Resumo
Um estudo sobre a composição gravimétrica dos resíduos sólidos urbanos no Brasil apresenta o papel de terceiro colocado no ranking dos resíduos, com 13,1\% da composição total. O objetivo deste trabalho é apresentar uma técnica de reciclagem e marmorização de papel, utilizando com insumo básico a carboximetilcelulose. Inicialmente adquiriu-se 50 folhas de papel já utilizado e cortou-se em pedaços pequenos. Posteriormente, foram colocados dentro do balde plástico com aproximadamente dois litros de água. Essa mistura ficou em repouso por $24 \mathrm{~h}$. Para a técnica de marmorização do papel reciclado utilizou-se a carboximetilcelulose, água e tinta à base de óleo de cores variadas. O resultado do processamento, descrito na metodologia, é um papel uniforme, com formato A4, uma textura rugosa fina em toda estrutura da folha, boa resistência mecânica à tração, sem aroma característico, uma coloração branco pálido (dependendo do papel a ser reciclado), propício para escrita e outras aplicações. A técnica de marmorização agrega valor ao papel e sugere diferentes aplicabilidades, inclusive artísticas.
\end{abstract}

Palavras-chave: Reciclagem de papel, carboximetilcelulose, impacto ambiental.

\begin{abstract}
A study on the gravimetric composition of municipal solid waste in Brazil, has the role as the third place in the ranking of waste with $13.1 \%$ of the total composition. The objective of this paper is to present a technique of marbling paper recycling and using Basic carboxymethylcelulose input. First acquired up to 50 sheets of paper already used and cut into small pieces. Subsequently, they were placed in plastic bucket with about two liters of water. This mixture was allowed to stand for 24 hours. For technical marbling of the recycled paper used is carboxymethylcelulose, water, oil-based ink of various colors. The result of the processing methodology is described in a uniform paper, A4 format with a fine rough texture throughout leaf structure, good mechanical resistance to traction without the aroma a pale white color (depending on the paper to be recycled), suitable writing and other applications. The technique of marbling, adds value to the material and suggests different applicability, including artistic.
\end{abstract}

Keywords: Recycling paper, carboxymethylcelulose, environmental impact. 


\section{INTRODUÇÃO}

O volume de recursos financeiros aplicados em 2012, para gestão dos resíduos sólidos no Brasil, atingiu a marca de $\mathrm{R} \$ 11,00 / \mathrm{hab} /$ mês. Este recurso está longe de ser o suficiente para a coleta de resíduos sólidos e demais serviços de limpeza urbana. Tais serviços devem atender plenamente a população, que tem apresentado crescimento expressivo, consumindo mais produtos e serviços e consequentemente descartando mais. No mesmo ano, foram geradas aproximadamente 64 milhões de toneladas de resíduos sólidos, o equivalente a $383 \mathrm{~kg} / \mathrm{ano} / \mathrm{hab}$. Em relação ao ano de 2011 houve um crescimento de 1,3\% no volume de lixo por habitante, enquanto que a população cresceu $0,9 \%$ no mesmo período (ABRELPE, 2012).

Neste cenário, um estudo sobre a composição gravimétrica dos resíduos sólidos urbanos no Brasil apresenta o papel de terceiro colocado no ranking dos resíduos, com $13,1 \%$ da composição total. Ficando atrás do plástico, com 13,5\%, e ocupando a primeira colocação está a matéria orgânica, com 51,4\% do total gerado (ABRELPE, 2012).

Um estudo sobre a composição gravimétrica dos resíduos sólidos feito no IFRJ CDUC apresentou, com $36,04 \%$, que o plástico é o material predominante na composição dos resíduos em estudo. O material orgânico é o segundo, com $28,36 \%$ da composição total. A terceira posição é ocupada pelo resíduo de papel, com $27,40 \%$. Anualmente são gerados pela instituição cerca de $800 \mathrm{~kg}$ de papel por ano (THODE-FILHO et al., 2014). O objetivo deste trabalho é apresentar uma técnica de reciclagem e marmorização de papel, utilizando como insumo básico a carboximetilcelulose.

\section{METODOLOGIA}

Os materiais utilizados para produção do papel reciclado foram: 50 folhas de papel ofício já utilizadas, 18 litros de água, liquidificador, tela plana produzida com tela de mosquiteiro fina e madeira com o tamanho de $210 \mathrm{~mm}$ x $297 \mathrm{~mm}$ de comprimento, bacia plástica, $80 \mathrm{~mL}$ de cola branca, balde plástico de $20 \mathrm{~L}$, jornal, $180 \mathrm{~mL}$ de álcool, espátula, calandra manual e micrômetro digital.

Inicialmente adquiriu-se 50 folhas de papel já utilizado e cortou-se em pedaços pequenos. Posteriormente, foram colocados dentro do balde plástico com aproximadamente dois litros de água. Essa mistura ficou em repouso por $24 \mathrm{~h}$. Após o repouso, colocou-se uma xícara do papel picado já amolecido no liquidificador, em seguida, acrescentou-se um litro de água e bateu-se por cerca de 2 minutos, ou até ficar com uma consistência de uma massa pastosa. Em seguida, despejou-se a massa batida em uma bacia grande e adicionou-se 15 litros de água e misturou-se. Foi adicionada, à massa, $80 \mathrm{~mL}$ de cola branca para aumentar a resistência mecânica do papel. Adicionou-se também $180 \mathrm{~mL}$ de álcool comercial. O mesmo não confere nenhuma propriedade mecânica ao papel, no entanto possui a função de inibir o odor desagradável ocasionado pela fermentação da celulose que é a matéria prima base do papel. Após a adição dos dois componentes, a massa pegou-se a peneira plana e mergulhou-se na bacia para a retirada de uma camada da massa que ficou depositada sobre a tela. Em seguida, deixou-se escorrer o excesso de água por alguns segundos. Colocou-se então a tela sobre uma folha de jornal dobrada e procedeu-se a retirada do excesso de água com um pano limpo. Deixou-se secar por cerca três a quatro horas. Depois do papel totalmente seco, utilizou-se uma espátula para retirada do papel da folha de jornal. Após o processo de secagem, utilizou-se uma calandra manual para uniformizar a folha e conferir uma espessura uniforme para as folhas de papel produzidas. As mesmas passaram duas vezes pelo equipamento e logo em seguida procedeu-se a medição da espessura com micrômetro digital, unidade por unidade produzida.

Para a técnica de marmorização do papel reciclado utilizou-se $60 \mathrm{~g}$ de carboximetilcelulose $\left(\mathrm{CH}_{2} \mathrm{CO}_{2} \mathrm{H}\right), 300 \mathrm{~mL}$ de água, tinta à base de óleo de cores variadas, Becker de vidro de $500 \mathrm{~mL}$, garfo, bandeja de fundo raso e palito de dente. Misturou-se a $\left(\mathrm{CH}_{2} \mathrm{CO}_{2} \mathrm{H}\right)$ com a água no Becker de vidro, utilizando o garfo para homogeneizar até obter uma consistência gelatinosa (gel). Despejou-se essa mistura na bandeja até cobrir sua superfície com uma camada fina. Adicionou-se tinta de cores variadas de maneira aleatória sobre o gel, pegou-se o palito e espalhou-se a tinta dando formas abstratas ou formando desenhos. Colocou-se o papel reciclado sobre a bandeja com o gel até que o papel aderisse às cores, retirou-se o papel da bandeja arrastando-o sobre a borda da mesma para retirar o excesso do gel. Desta forma, as cores e formas que estavam sobre o gel foi transferido para o papel. Colocou-se o papel para secar sobre uma superfície plana por cerca de $24 \mathrm{~h}$ ou poder-se-ia operar até que o processo de secagem estivesse completo. 


\section{RESULTADO E DISCUSSÃO}

O resultado do processamento descrito na metodologia é um papel uniforme, com formato A4, totalizando 140 folhas, uma textura rugosa fina em toda estrutura da folha, boa resistência mecânica à tração, sem aroma característico, uma coloração branco pálido (dependendo do papel a ser reciclado), propícia para escrita e outras aplicações. $O$ papel reciclado apresentou uma espessura com variação, entre as folhas produzidas, de $0,39 \mathrm{~mm}$ a $0,48 \mathrm{~mm}$, dependendo da suspensão de fibras (Figura 1a-g).

Quando recoberto por uma fina camada de $\mathrm{CH}_{2} \mathrm{CO}_{2} \mathrm{H}$, confere-se ao papel reciclado uma característica impermeável, possibilitando a fixação de tinturas e pigmentos aplicados (Figura 1h). Para realização da técnica de marmorização, procurou-se utilizar um insumo que fosse solúvel em água, tanto a frio quanto a quente (por conta do seu baixo custo), e que possibilitasse a formação de soluções e géis. A mesma apresenta uma grande facilidade de aplicação, além de ser um material fisiologicamente inerte. Vale ressaltar que, além das características apresentadas acima, a $\mathrm{CH}_{2} \mathrm{CO}_{2} \mathrm{H}$ é um material biodegradável.

A reciclagem deu ao lixo um valor econômico que antes não existia e os ganhos proporcionados pela reciclagem do lixo se devem ao fato de ser mais econômico produzir a partir desse processo do que de matérias-primas virgens, isto porque se utiliza menos energia, matéria-prima e
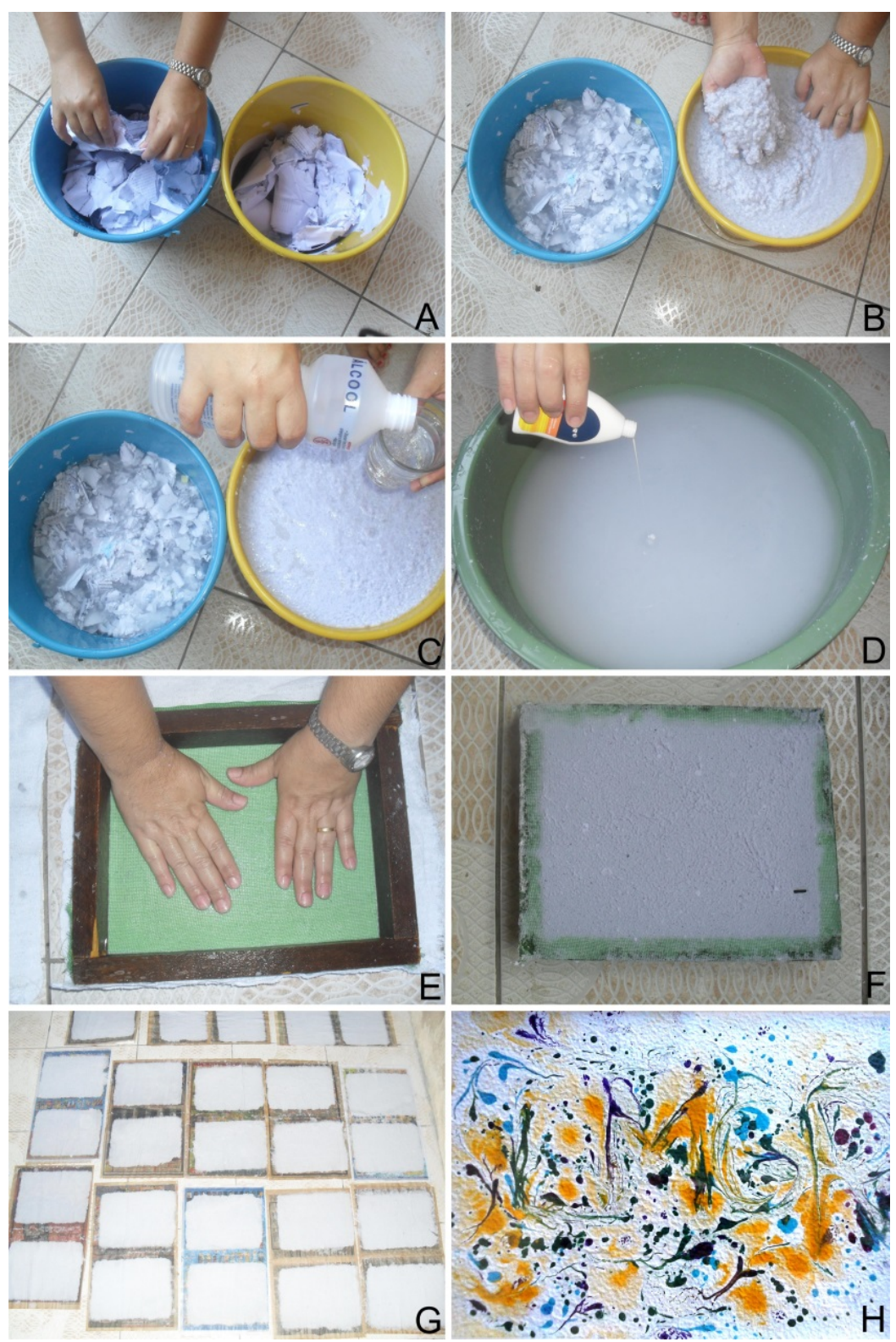

Figura 1. Passo a passo da técnica de marmorização do papel reciclado 
recursos hídricos. No entanto, no Brasil, grande parte do papel reciclado produzido consiste de $75 \%$ de papel pré-consumo e $25 \%$ pós-consumo. Logo, grande parte da matéria-prima utilizada para a fabricação do papel reciclado são sobras de produção das próprias indústrias produtoras de papel e celulose, ou mesmo de indústrias gráficas. Não se pode negar a importância da reciclagem e os ganhos que ela pode representar quanto à economia de materiais e recursos naturais $(\mathrm{CAL}$ DERONI, 2003).

O Brasil está sendo percebido, mundialmente, devido ao volume expressivo de recuperação de papéis recicláveis que, após o descarte, são convertidos em novos produtos que retornam à cadeia produtiva. $\mathrm{O}$ esclarecimento da população sobre a preservação do ambiente, campanhas que incentivam o descarte adequado e a coleta seletiva têm colaborado fortemente para que a indústria de reciclagem se desenvolva e cresça cada vez mais no País. Foi registrado, em 2011, que o consumo aparente de papel no país registrou 9,6 milhões de toneladas e a recuperação de aparas foi de 4,4 milhões de toneladas (BRACELPA, 2011). Portanto, neste trabalho são sugeridas novas metodologias na tentativa de reduzir-se o descarte inadequado destes resíduos.

Em virtude de tantos desafios que permeiam a gestão de resíduos, vale ressaltar os esforços governamentais para disciplinar o problema dos Resíduos Sólidos Urbanos, a exemplo do Decreto Federal $n^{\circ}$ 5.940/06 e do Decreto $n^{\circ} 40.645 / 07$, do Governo do Estado do Rio de Janeiro, que instituíram a Coleta Seletiva Solidária e a obrigatoriedade de separação dos resíduos recicláveis na fonte geradora, além da aprovação da Lei ${ }^{\circ}$ 12.305/10 que instituiu a PNRS.

Ela surge para tentar minimizar o problema dos resíduos, uma vez que agora não apenas o governo, mas os produtores e até os consumidores são responsáveis pela destinação e tratamento correto do seu material inservível, através do processo de logística reversa de pós-consumo, no qual constituem-se bens de pós-consumo os produtos em fim de vida útil ou usados com possibilidade de utilização e os resíduos industriais em geral (BARBIERI, 2004; CHAVES; BATALHA, 2006; SOUZA et al., 2012). Estabelece também uma responsabilidade compartilhada entre governo, indústria, comércio e consumidor final no gerenciamento e na gestão dos resíduos sólidos.

Para dar conta destas demandas sociais é preciso elaborar planos de gestão integrada para os resíduos sólidos urbanos, integrando-se os aspectos econômicos, sociais, ambientais e contemplando-se todas as fases do fluxo que integram cada classe de resíduos, desde a sua geração, coleta, transporte até a destinação final, levando-se em conta as alternativas de reutilização/reciclagem e beneficiamento dos diferentes tipos de resíduos, em particular do papel. Trata-se, portanto, de um sistema complexo, no qual interagem agentes públicos, privados e movimentos sociais (MONTEIRO, 2001; GONÇALVES, 2006; THODE-FILHO; CALDAS, 2008a; 2008b; SILVA et al., 2010; MEIRELES; ALVES, 2011).

Além disso, este sistema possui uma clara contribuição social quando identifica e trata como elo de uma cadeia a participação dos catadores de materiais recicláveis (GONÇALVES, 2006; VARANDA; BOCAYUVA, 2009; BESEN, 2011). Embora não existam estatísticas precisas sobre o número de catadores, estima-se que, no espaço urbano, exista pelo menos um catador para cada mil habitantes e três em cada 10 catadores gostariam de continuar na cadeia produtiva da reciclagem mesmo tendo alternativas de trabalho (RODRIGUES, 2011).

\section{CONCLUSÃO}

Este trabalho apresentou uma técnica de reciclagem que pode proporcionar uma estratégia de mitigação do impacto ambiental provocado pelo descarte inadequado do papel residual. Os processos simplificados, as matérias-primas não dispendiosas e os equipamentos rotineiros estimulam positivamente a sua produção. Além da reciclagem do papel, a técnica de marmorização agrega valor ao material e sugere diferentes aplicabilidades. Neste sentido, esta técnica permite, através da preparação de uma solução aquosa viscosa, a adição de tintas que vão garantir um design semelhante ao mármore liso ou rocha quando em contato com uma superfície absorvente, podendo ser papéis ou tecidos. O resultado visual, percebido neste trabalho, possibilita o emprego da técnica para encadernação em cartões de visita, bloquinhos, papéis de carta, moldura de fotos, entre outros.

Sugere-se então, a partir dos resultados deste estudo, a possibilidade de avaliar as potencialidades de uma organização beneficiar este resíduo, possibilitando trabalho e renda a diferentes grupos sociais ou através de cooperativas organizadas de catadores. 


\section{REFERÊNCIAS}

ABRELPE, 2012. Panorama dos Resíduos Sólidos do Brasil. Disponível em: <www.abrelpe.org.br>. Acesso em 14 de fev. 2014.

BARBIERI, J. C. Gestão Ambiental Empresarial: conceitos, modelos e instrumentos. São Paulo: Saraiva, 2004.

BESEN, G. R. Coleta seletiva com inclusão de catadores: Construção participativa de indicadores e índices de sustentabilidade [Tese de doutorado]. São Paulo: Faculdade de Saúde Pública da Universidade Estadual de São Paulo, 2011.

BRACELPA, 2011. Evolução do Consumo Brasileiro de Aparas. Disponível em:

<http://www.bracelpa.org.br/bra2/?q=node/141>. Acesso em: 10 de fevereiro de 2014.

BRASIL, 2010. Decreto N 7.404/2010 - Casa Civil da Presidência da República do. (23 de 12 de 2010). Planalto. Disponível em: <www.planato.gov.br>. Acesso em 07 de nov. 2013.

BRASIL. Lei n ${ }^{o} 12.305$, de 2 de agosto de 2010. Institui a Política Nacional de Resíduos Sólidos; altera a Lei no 9.605, de 12 de fevereiro de 1998; e dá outras providências.

CALDERONI, Sabetai. Os bilhões perdidos no lixo. 4. ed. São Paulo: Humanitas, 2003.

CHAVES, G. de L. D. e M. O. BATALHA (2006) Os consumidores valorizam a coleta de embalagens recicláveis? Um estudo de caso da logística reversa em uma rede de hipermercados. Revista Gestão e Produção, (13) 3, 449-461.

GONÇALVES, P. Gestão de Resíduos Sólidos: Conceitos, Experiências e Alternativas. In: Seminário Cadeia Produtiva da Reciclagem e Legislação Cooperativista, Juiz de Fora, MG, 2006.

MEIRELES, M. E. F.; ALVES, J. C. M. Gestão de resíduos: As possibilidades de construção de uma rede solidária entre associações de catadores de materiais recicláveis. In. VII Congresso Nacional de Excelência em Gestão, 2011.

MONTEIRO, J. H. P.; ZVEIBIL, V. Z. Manual de gerenciamento integrado de resíduos sólidos. Rio de Janeiro: IBAM, 2001.
RODRIGUES, L. F. O. (2011) Saneamento e cooperativas de catadores de materiais recicláveis. Revista do Curso de Direito da UNIABEU, (1) 1.

SILVA, E. R.; CARMO, E. C. L.; GONÇALVES, P.; BENTO, R. F. P.; MATTOS, U. A. O. Planejamento participativo para a implantação da coleta seletiva solidária no estado do Rio de Janeiro, RJ: Ações e resultados. In. VI Congresso Nacional de Excelência em Gestão, 2010.

SOUZA, M. T. S.; PAULA, M. B.; SOUZA-PINTO, H. (2012) O papel das cooperativas de reciclagem nos canais reversos pós-consumo. Revista de Administração de Empresas, (52) 2, 246-262.

THODE-FILHO, Sergio; MARQUES, Aline de Jesus; SANTOS, Joyce; RIBEIRO, Karen Ferraz; MEDEIROS, Monica Raquel Amaral Moreira de; SANTOS, Patryck Gonçalves; FRANÇA, Suelen de Santana; Um estudo sobre a composição gravimétrica dos resíduos sólidos do IFRJ Campus Duque de Caxias, RJ, Revista Eletrônica em Gestão, Educação e Tecnologia Ambiental, 2014. [no prelo]

THODE-FILHO, S. CALDAS, M. A. F. O uso da tecnologia da informação que integra a cadeia produtiva nas pequenas empresas do comércio varejista do município do Rio de Janeiro. In: IV Congresso Nacional de Excelência em Gestão, 2008a.

THODE-FILHO, S. CALDAS, M. A. F. O gerenciamento da informação nas micro e pequenas empresas. In: Simpósio de Excelência em Gestão e Tecnologia, 2008b.

VARANDA, A. P. M.; BOCAYUVA, P. C. C. Tecnologia Social, Autogestão e Economia Solidária. Rio de Janeiro: FASE, 2009. 